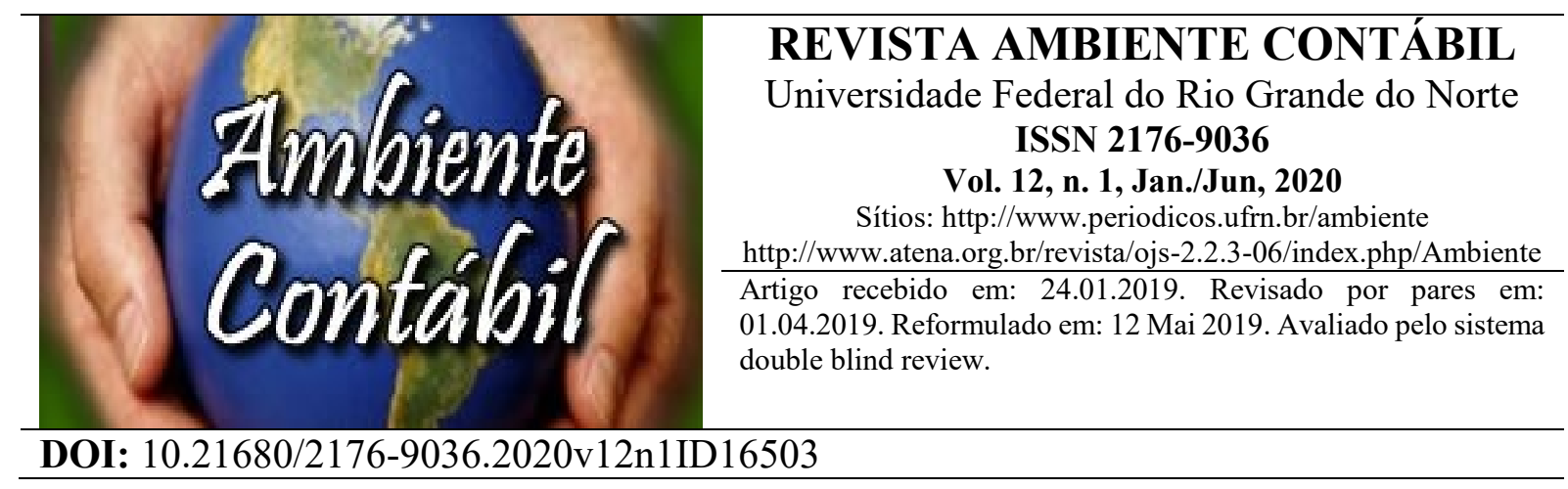

\title{
O nível de disclosure em Organizações do Terceiro Setor (OTS) no Estado do Ceará
}

The level of disclosure in Organizations of the Third Sector (OTS) in the State of Ceará

El nivel de divulgación en Organizaciones del Tercer Sector (OTS) en el Estado de Ceará

\section{Autores}

\section{Roberto Sérgio do Nascimento}

Doutor em Contabilidade, Professor de Contabilidade, Orçamento e Auditoria do Setor Público da Universidade Federal do Ceará, Departamento de Contabilidade. Auditor do Tribunal de Contas da União (TCU), Secretaria de Estratégias de Combate à Corrupção. Av. da Universidade, 2431, Telefone: (85) 33667801/02, Identificadores (ID):

Lattes: http://buscatextual.cnpq.br/buscatextual/visualizacv.do?id=K4778232P5

ORCID iD: https://orcid.org/0000-0001-8217-9267

E-mail: robertosdn75@gmail.com

\section{Mirela Márjorie Silva Rabelo}

Contadora, Universidade Federal do Ceará (UFC), Departamento de Contabilidade, Av. da Universidade, 2431, Benfica, Fortaleza-CE, Cep. 60020-180 (85) 99601.1138,

Identificadores (ID):

ORCID I iD: https://orcid.org/0000-0001-7825-0892

\section{Ricardo Viotto}

Advogado, Esp. Direito Processual Civil. Av. Duque José Guimarães, 1130, Cambeba, Fortaleza-CE, Cep. 60.822-220 (85) 999123026, Identificadores (ID):

ORCID iD: https://orcid.org/0000-0002-0173-9195

E-mail: ricardoviotto@yahoo.com

\section{Resumo}

Objetivo: O presente trabalho se propõe a avaliar o nível de disclosure apresentado pelas Organizações do Terceiro Setor no Estado do Ceará em relação aos usuários externos, como forma de reduzir a assimetria informacional entre os agentes internos e externos em alusão à Teoria da Agência.

Metodologia: Com base na legislação vigente e na revisão da literatura, selecionou-se um conjunto de itens de divulgação obrigatória e voluntária para compor o indicador de disclosure (ID), o qual foi utilizado para calcular o respectivo nível de disclosure das 100 maiores 
organizações do Estado do Ceará. A construção do índice tomou como base escala dicotômica, do tipo 0 (zero) e 1 (um), representando respectivamente ausência e presença de informação.

Resultados: revelaram que o nível de evidenciação das informações voluntárias (39\%) foi maior que as de natureza obrigatória (2\%). Disto decorre que tanto a transparência como o processo de accountability destas instituições se encontram prejudicados, mostrando-se os resultados contraditórios, na medida em que essas entidades deveriam atuar provendo informações financeiras e de desempenho, e não ao contrário.

Contribuição do Estudo: o estudo evidencia que o nível de disclousure das OTS do Estado do Ceará foi considerado insatisfatório, na medida que as informações obrigatórias e voluntárias totalizaram um percentual de $41 \%$ dos itens pesquisados.

Palavras-chave: Organização do Terceiro Setor, Disclosure, Informação voluntária e obrigatória; Indicador.

\begin{abstract}
Purpose: this paper aims to evaluate the level of disclosure presented by Third Sector Organizations in the State of Ceará in relation to external users as a way to reduce informational asymmetry between internal and external agents in allusion to Agency Theory.
\end{abstract}

Methodology: Based on current legislation and the review of the literature, a set of mandatory and voluntary disclosure items was selected to compose the disclosure indicator (ID), which was used to calculate the respective level of disclosure of the 100 largest organizations State of Ceará. The construction of the index was based on a dichotomous scale, of type 0 (zero) and 1 (one), representing respectively absence and presence of information.

Results: revealed that the level of disclosure of voluntary information (39\%) was greater than that of mandatory information (2\%). It follows that both the transparency and the accountability process of these institutions are undermined, showing the contradictory results, insofar as these entities should act by providing financial and performance information, not the other way around.

Contribution of the Study: the study shows that the disclousure level of the State of Ceará was considered unsatisfactory, as mandatory and voluntary information totaled a percentage of $41 \%$ of the items surveyed.

Keywords: Organization of the Third Sector, Disclosure, Voluntary and obligatory information; Indicator.

\title{
Resumen
}

Objetivo: el presente trabajo se propone evaluar el nivel de divulgación presentado por las Organizaciones del Tercer Sector en el Estado de Ceará en relación a los usuarios externos, como forma de reducir la asimetría informacional entre los agentes internos y externos en alusión a la Teoría de la Agencia.

Metodología: Con base en la legislación vigente y en la revisión de la literatura, se seleccionó un conjunto de ítems de divulgación obligatoria y voluntaria para componer el indicador de disclosure (ID), el cual fue utilizado para calcular su nivel de divulgación de las 100 mayores 
organizaciones del mismo, Estado de Ceará. La construcción del índice tomó como base escala dicotómica, del tipo 0 (cero) y 1 (uno), representando respectivamente ausencia y presencia de información.

Resultados: revelaron que el nivel de evidencia de las informaciones voluntarias $(39 \%)$ fue mayor que las de naturaleza obligatoria (2\%). De ello se desprende que tanto la transparencia como el proceso de accountability de estas instituciones se ven perjudicadas, mostrando los resultados contradictorios, en la medida en que esas entidades deberían actuar proporcionando informaciones financieras y de desempeño, y no al revés.

Contribución del Estudio: el estudio evidencia que el nivel de disclousure de las OTS del Estado de Ceará fue considerado insatisfactorio, en la medida que las informaciones obligatorias y voluntarias totalizaron un porcentaje del $41 \%$ de los ítems encuestados.

Palabras clave: Organización del Tercer Sector, Disclosure, Información voluntaria y obligatoria; Indicador.

\section{Introdução}

A participação das Organizações do Terceiro Setor (OTS) é cada vez maior no cenário nacional. Rocha (2019) informa que existem cerca de 400.000 OTS no Brasil, o que demonstra a participação crescente deste tipo de entidade na estrutura da sociedade brasileira.

No país, sua origem remonta à década de 90 , na qual o Governo Federal, sob o argumento de diminuir o tamanho do Estado brasileiro, propôs à sociedade a extinção de diversos órgãos pertencentes à Administração Pública Federal, com a consequente delegação dos serviços por eles executados ao chamado Terceiro Setor. Advogava-se que haveria ganhos orçamentários, financeiros e, sobretudo, de eficiência, visto que a manutenção desses serviços por unidades pertencentes ao governo, em geral, possui custos mais elevados, enquanto que uma vez ofertados por estruturas privadas, seriam menos onerosos. Aprovada a proposta no âmbito federal, as ideias foram facilmente disseminadas para Estados e municípios.

Para este tipo de organização, a transparência é vital. Se de um lado cobrem um amplo escopo de grupos (doadores, voluntários, público em geral, iniciativa privada etc.), por outro, são beneficiárias de "facilidades" relativas ao financiamento indireto dos serviços públicos descentralizados que pode se dá mediante isenções tributárias ou transferências orçamentárias.

Numa dimensão maior (O’Dwyer, \& Unerman, 2008), a transparência se encontra incluída no conceito de accountability que envolve a divulgação de informações, com vistas a possibilitar a participação dos stakeholders sobre a avaliação de desempenho das atividades realizadas. Cabedo et al (2017) destacam que a transparência está relacionada com todos estes conceitos, notadamente com o disclosure.

$\mathrm{O}$ disclosure, na verdade, deve ser considerado uma resposta às exigências do governo $\mathrm{e}$ de outros usuários como forma de reduzir a assimetria informacional entre os agentes internos e externos (investidores, público interno, empregados, gestores etc.) em alusão à Teoria da Agência. Há quem indique que as informações divulgadas ocorrem em razão do fortalecimento da imagem dessas entidades, por servirem à sociedade, reforçando a necessidade de apoio financeiro por parte dos seus principais doadores (Christense, \& Mohr, 2003, Taylor, \& Warburton, 2003). Outros, citando-se Striebing (2017), como instrumento de avaliação de gestão por parte de gerentes e funcionários em relação aos seus pares. 
Nem toda informação que se divulga é obrigatória. Neste quesito há uma nítida distinção entre a confiabilidade da informação prestada e os níveis de informação voluntária que elas prestam de forma espontânea. Há uma preocupação significativa da acadêmica quanto esta última modalidade de informação (Hyndman, \& McConville, 2016, Gandía, 2010).

Neste contexto é que se propõe avaliar o disclosure das OTS, assim entendido como a transparência dos riscos, benefícios e implicações econômicas associados. Para Goulart (2003), o termo possui relação com à abertura da empresa por meio da divulgação de informações, garantindo a transparência corporativa diante do público e dos participantes de mercado.

O trabalho se justifica em razão do crescimento dessas modalidades de organizações no país, bem como a utilização maciça de organizações sociais (OS) e organizações sociais de interesse público (OSCIP) pela Administração Pública em atividades que anteriormente cabiam somente ao Estado. Logo, há uma necessidade premente em saber se os mecanismos de accountability e transparência de que dispõem se encontram funcionando.

$\mathrm{O}$ presente artigo possui o seguinte problema de pesquisa: qual o nível de disclosure apresentado pelas Organizações do Terceiro Setor no Estado do Ceará aos usuários externos? Entende-se que, dessa forma, poderão cumprir os requisitos básicos relacionados à geração de serviços, tornando-as mais confiáveis e atrativas aos investidores.

O trabalho está estruturado nas seguintes seções: além da presente introdução, a segunda trata da fundamentação teórica que se compõe a sistemática de disclosure em organização do terceiro setor; a terceira, a metodologia empregada; a quarta, a análise e discussão dos resultados obtidos e a última, as conclusões do estudo.

\section{Revisão da Literatura}

O disclosure possui um papel fundamental no funcionamento do mercado de capitais, tendo a literatura enfatizado a existência de diversos fatores capazes de afetar o nível de decisão dos stakeholders. A busca por uma estrutura ideal acerca do tema é uma incógnita entre os investigadores, daí as mais diversas combinações entre variáveis para identificação da melhor estrutura.

De uma maneira geral, o disclosure ou evidenciação está relacionado ao fornecimento aos usuários de um conjunto mínimo de informações de natureza patrimonial, econômica, financeira, legal, física e social que lhes possibilitem o conhecimento e a análise da situação da Entidade. Nas empresas está diretamente associado à necessidade que usuários possuem em tomar decisões baseadas nas informações que são divulgadas.

A temática vem sendo discutida mais intensamente desde a década de 80 (Verrecchia, 1983, Dye, 1985) ganhando uma atual relevância em função da globalização dos mercados que exige o uso de práticas diversificadas com vista a aproximar "principal" dos "agentes" (Teoria da Agência).

De acordo com os idealizadores dessa teoria, Jensen e Meckling (1976), a crise econômica de 1929 que levou a desconcentração da propriedade e à criação de um novo modelo de controle empresarial possibilitou que fosse observado que os novos atores destas corporações se comportavam mediante uma rede de contratos explícitos e implícitos. Daí surgiram conceitos, tais como: agente e principal, assimetria de informações, conflito de interesses e custos de agência utilizados para explicar as relações que passaram a reger as organizações surgidas pós 1929. A assimetria de informações, particularmente, foi considerada como ponto de partida para compreensão dos vários modelos de disclosure (Verrecchia, 2001).

Essa relação - disclosure versus assimetria - já foi objeto de vários estudos por parte dos pesquisadores que utilizaram canais tradicionais de comunicação visando à ampliação da 
qualidade da informação financeira (relatórios anuais, informações de analistas financeiros, análises de rentabilidade etc.). Atualmente, estuda-se o nível do disclosure face a disseminação de conteúdo através da Internet (Ettredge, Richardson, \& Scholz, 2002, Marston, \& Polei, 2004, Gajewski, \& Li, 2015), enquanto que outros autores (Bolívar, Pérez, \& Hernández, 2006) já vêm a associação das informações que são divulgadas por este canal levando em consideração à cultura administrativa adotada pelo país, se de origem Anglosaxônica, Sulamericana ou proveniente da Europa Central.

Em geral, a literatura especializada destaca a importância do nível de disclosure em relação ao aspecto financeiro das informações divulgadas (Saxton, Kuo, \& Ho, 2011, Gandía, 2011, Saxton, \& Guo, 2011). No Brasil, os estudos tem enfatizado o disclosure sob a perspectiva da Contabilidade, envolvendo temas, como risco de mercado, mobilidade de capitais internacionais, ciclo operacional e financeiro, divulgação voluntária, eficiência e governança corporativa (Goulart, \& Carvalho, 2004, Quinteiro, \& Medeiros, 2005, Crozatti, Cordeiro, \& Campos, 2006, Salotti, Yamamoto, \& Pimentel, 2007, Malaquias, \& Carvalho, 2008, Santos, Costa, Correa, \& Santos, 2011). Atualmente, esse rol de temas se tornou mais abrangente, pois além das questões econômicas e financeiras, foram incluídos aspectos socioambientais, responsabilidade social corporativa e sustentabilidade empresarial.

A divulgação de informações pode ser tanto obrigatória como voluntária. Diz-se obrigatória quando abrange requerimentos para registro das companhias abertas e demais informações periódicas expedidas pelas comissões de valores mobiliários ou associações de cada país. Notabilizaram-se aquelas de caráter financeiro, sendo as principais as demonstrações contábeis e relatórios anuais. Nas economias emergentes, o disclosure financeiro tem sido examinado intensamente devido a necessidade de recursos e ao potencial de crescimento que dispõem.

Kavitha e Nadagopal (2011) mencionam que a extensão das informações que são divulgadas varia entre os países e depende do rigor do sistema legal do país, enquanto que Charumathi e Ramesh (2015) vêm diferenças de ordem cultural, sendo a globalização um contraponto neste processo. Contudo, no centro da questão reside o aumento da liquidez do mercado de ações com a consequente diminuição dos custos de transação, visto que um bom disclosure corporativo deve ser minimamente complexo e transparente (Fick, 2010).

Embora qualquer divulgação em excesso possa ser considerada como informação voluntária, Beyer, Cohen, Lys e Walther (2010) evidenciam que há um crescimento da demanda em relação à divulgação de informação obrigatória. A primeira razão, refere-se que gerentes e administradores das empresas possuem à disposição uma quantidade maior de informações sobre a lucratividade atual e futura das empresas que os usuários externos. A segunda, é inerente as economias modernas - separação entre proprietários e controle - que possibilita com que os primeiros não tenham plena certeza das decisões a serem tomadas.

A seu turno, informação voluntária se refere a quaisquer informações financeiras e não financeiras divulgadas além dos relatórios financeiros (Dhaliwal, Li, Tsang, \& Yang, 2011, FASB, 2014), tais como: informações estratégicas, meio ambiente, desempenho, preço das ações ou previsões de ganhos. Estudos destacam que o tipo de informação voluntária depende dos custos e dos benefícios a ela associados, daí se afirmar que representa o exercício do poder discricionário por parte dos gerentes e executivos sob aspectos específicos: governança corporativa (Ho \& Wong, 2001), desempenho sustentável (khan, Serafeim, \& Yoon, 2016, Ng, \& Rezaee, 2015) e conhecimentos prévios dos executivos (Bamber, Jiang, \& Wang, 2010).

A variedade e o tipo de informação são distintos ao passo que Goulart (2003) destaca que um disclosure não é só feito de informações positivas. Para o autor, para a garantia da 
transparência, faz-se necessário que as empresas divulguem tanto as informações positivas como também as negativas.

Considerando o escopo normativo brasileiro, as organizações do terceiro setor são obrigadas a preparar relatórios específicos sobre suas atividades e situação patrimonial com determinada periodicidade. A expressão Terceiro Setor designa, segundo Fernandes (2002), as iniciativas oriundas da sociedade em prol do bem público. Essa terminologia é empregada ao lado de outras, a exemplo de organização não-governamental e sociedade civil sem fins lucrativos.

As demonstrações contábeis fornecidas pela contabilidade são os instrumentos de que elas se servem para tomar as decisões referentes à administração dos seus recursos, a fim de atingir os objetivos a que se propõem. Segundo Araújo (2008), esta é a semelhança mais significativa entre as entidades de ambos os setores.

No Brasil, o Governo Federal decidiu normatizar a temática por intermédio das Leis $\mathrm{n}{ }^{\mathrm{o}}$ 9.637/98 e 9.790/1999. Enquanto a primeira trata da qualificação das entidades como organizações sociais, a segunda dispõe acerca da qualificação de pessoas jurídicas de direito privado, sem fins lucrativos, como organizações da sociedade civil de interesse público.

No caso de OTS, comumente voltadas às ações de interesse público, o disclosure relaciona-se com a própria característica operacional desse tipo de entidade. Ao contrário das empresas de mercado, que priorizam a agregação de valor a elas mesmas e à maximização da riqueza de seus acionistas, as OTS priorizam o cumprimento de sua missão social, destacandose por possuírem restrições distributivas de riqueza e a obrigatoriedade de reinvestimento de possíveis superávits.

Por intermédio do disclosure, a empresa pode oferecer elementos para reduzir a assimetria informacional. É neste sentido que as Organizações do Terceiro Setor (OTS) devem receber uma abordagem específica para avaliar o nível de evidenciação demonstrado, tendo em vista os seus objetivos sociais peculiares, os quais transcendem aos aspectos econômico-financeiros.

Inicialmente, os estudos se preocupavam, basicamente, em identificar que atributos mais impactavam o disclosure nas organizações, tanto positiva, quanto negativamente. Core (2001) analisou fatores interna corporis, enquanto que outros autores partiram de fatores externos (condições legais, políticas, sociais e de mercado). Beattie (2004) associou as informações divulgadas pelos analistas financeiros, enquanto que Healy e Papepu (2001) indicaram transações no mercado de capitais, talento dos gerentes, litígios, custos de propriedade etc.

Analisando-se a legislação vigente brasileira, observa-se 10 (dez) itens de divulgação obrigatória por parte destas entidades: disponibilização das demonstrações contábeis aos seus usuários, publicação na imprensa oficial ou privada, em qualquer de suas modalidades, publicação de notas explicativas, segregação de contas de receita e despesa por atividade, informações sobre os critérios de apuração das receitas e despesas, demonstração das isenções previdenciárias (INSS), montante das subvenções recebidas, descrição das condições (taxas, prazos etc.) das obrigações de longo prazo, auditoria independente/externa ou interna e realização de convênio com órgão público.

No tocante à informação voluntária, também houve um crescimento dos aportes por parte da literatura especializada. A depender do tipo de organização, os países optam em identificar um portfólio mínimo de informação obrigatória, deixá-la por completo a critérios das entidades ou em formato misto envolvendo ambas as modalidades de informações.

Neste sentido, a quantidade de estudos científicos acerca do formato assumido e da qualidade das informações não voluntárias também é ampla. Amagoh (2015), por exemplo, destacou que a credibilidade e eficiência das ONGs estão relacionadas às informações divulgadas sobre sustentabilidade a longo prazo, aspectos centrais da entidade, planejamento 
estratégico, governança, conselho de administração, recursos humanos, parcerias, financiamento, imagem etc.

Saxton, Kuo e Ho (2011), ao analisaram 4 (quatro) fatores (capacidade organizacional, estratégia, ambiente e governança) que poderiam ampliar a decisão de divulgação de informação voluntária em ONGs em Taiwan, encontraram evidências de que há uma maior probabilidade de que o disclosure ocorre em organizações pequenas, com baixos índices de ativos/endividamento e com conselho de administração com elevado número de participantes externos. Os autores destacaram ainda que a informação divulgada de forma voluntária não é suficientemente eficaz em promover accountability.

Bhojraj, Blacconiere e D'Souza (2004) analisaram o impacto do disclosure em serviços regulados. Os autores concluiram que empresas de serviços públicos tendem a divulgar menos informações estratégicas com vista a parecerem "fracas" perante os reguladores. Por outro lado, concessionárias cuja viabilidade em um ambiente desregulamentado é mais incerta, tendem a fornecer mais informações, a menos que enfrentem uma ameaça maior dos concorrentes.

Os mesmos atributos foram estudados por Hail (2002) ao examinar um conjunto de empresas suíças. Desta vez, o autor confirmou a existência de associação negativa entre disclosure e o custo de capital próprio, persistindo mesmo após o controle de variáveis que potencialmente influenciariam no resultado, como atributos de risco e tamanho da empresa.

Eng e Mak (2003) selecionaram duas variáveis para fins de análise: estrutura de capital e composição da diretoria sobre o disclosure voluntário. Os autores evidenciaram que ambas as variáveis afetam positivamente a divulgação de informação, contudo um aumento do número de diretores externos reduz a divulgação corporativa, bem como a existência de grandes empresas e pequenas companhias com alto endividamento aumentam a divulgação.

Lanzana (2004) buscou eventual relação entre governança e disclosure. Foram estudadas as variáveis direito de controle, diferença entre direito de controle e direito de fluxo de caixa do acionista controlador (DIF), número de membros do conselho de administração, Independência e presença do presidente da empresa como presidente do conselho de administração (INDEP). Como resultado, a variável DIF corroborou o efeito de substituição entre nível de disclosure e governança, enquanto que a significância da variável INDEP confirmou o efeito de complementação entre estas duas variáveis, mostrando que o grau de independência do conselho é relevante para empresas que hoje não praticam disclosure voluntário passem a fazê-lo.

Destarte, os itens sobre disclosure voluntário serão baseados nos trabalhos acima. Serão selecionados 10 itens que apresentaram relação direta com o contexto das OTS, declaração de metas, objetivos e missão da organização, descrição dos serviços prestados, fatores críticos de sucesso, estrutura organizacional, relatório de atividades, sumário dos resultados históricos, custos da atividade de captação de recursos, políticas, projetos e investimentos, resultados e desempenhos projetados e evidenciação dos recursos com finalidade exclusiva.

\section{Procedimentos Metodológicos}

O universo foi composto das organizações que participam do terceiro setor no País, enquanto que a base amostral se refere às 100 maiores organizações do Estado do Ceará, coletadas a partir do site OngsBrasil (www.ongsbrasil.com.br). A escolha do site atende ao objetivo de validação da amostra, dado que no Brasil não existe catalogação oficial da totalidade dessas entidades, sendo que as informações foram coletadas no ano de 2018.

Para geração dos dados da pesquisa - relativo aos itens constantes das Tabelas 1 e 2 a seguir -, visitou-se todos os sites das organizações identificadas na amostra, à semelhança de 
autores como Gandia (2009), Tremblay-Boire e Prakash (2014) que destacam a importância da internet como instrumento para melhoria da transparência e accountability. A partir das informações e dados disponibilizados nos sites analisados, adotou-se a mesma escala dicotômica de Bhojraj et al. (2004), em que 0 (zero) representa a ausência e 1 (um) a presença da informação, associado a ausência de peso diferenciado para o cálculo da pontuação final da entidade em análise.

Com base na legislação vigente e na literatura científica sobre o tema, selecionou-se um conjunto de 10 itens para cada modalidade de informação (obrigatória e voluntária) para compor o indicador de disclosure (ID), o qual foi utilizado para calcular o respectivo nível de disclosure das 100 maiores OTS do Estado do Ceará, que apresentam um website.

Para a construção do indicador de disclosure foram adotados critérios de características quantitativas e qualitativas para cada item, basicamente constatando-se a presença da informação analisada. Os indicadores foram, portanto, o resultado da análise em conjunto dos itens selecionados.

A tabela 1 contém os 10 itens obrigatórios com as respectivas siglas. Sob o aspecto normativo brasileiro, as entidades são obrigadas, por força de lei, a preparar relatórios específicos sobre suas atividades e situação patrimonial com determinada periodicidade.

\section{Tabela 1}

Exigências de informações obrigatórias com base na legislação brasileira

\begin{tabular}{llc}
\hline Variável & Itens de Informação Obrigatória (Mandatory Disclosure) & NBC T 11 e ITG \\
\hline DISP & Disponibilização das demonstrações contábeis aos seus usuários \\
PUBL & $\begin{array}{l}\text { Publicação na imprensa oficial ou privada, em qualquer de suas } \\
\text { modalidades }\end{array}$ & $22 /$ ITG \\
NOTA & Publicação de Notas Explicativas & $22 /$ ITG \\
SEGR & Segregação de contas de receita e despesa & $27 /$ ITG \\
CRIT & Informações sobre os critérios de apuração das Receitas e Despesas & $12 /$ ITG \\
ISEN & Demonstração das isenções previdenciárias (INSS) & 27, a/ITG \\
SUBV & Montante das subvenções recebidas & $11 /$ ITG \\
OBLP & Descrição das condições (taxas, prazos etc.) das obrigações de longo & $27, \mathrm{~d} / \mathrm{ITG}$ \\
AUD & prazo & $27, \mathrm{~h} / \mathrm{ITG}$ \\
CONV & Auditoria Independente/Externa ou Interna & $11.1 .1 \mathrm{NBC}$ \\
\hline
\end{tabular}

Fonte: dados da pesquisa.

A tabela 2 contém 10 itens voluntários selecionados a partir de estudos constantes da revisão da literatura, tendo por base revisão da literatura internacional. 
Tabela 2

Exigências de informações voluntárias com base na revisão da literatura

\begin{tabular}{lll}
\hline Variável & Itens de informação voluntária (Voluntary Disclosure) & \multicolumn{1}{c}{$\begin{array}{l}\text { Revisão da } \\
\text { Literatura }\end{array}$} \\
\hline DMOM & Declaração de Metas, Objetivos e Missão da Organização & $\begin{array}{l}\text { Bhojraj (2004), } \\
\text { Botosan (1997), Eng } \\
\text { e Mak (2003) }\end{array}$ \\
SERV & Descrição dos Serviços Prestados & $\begin{array}{l}\text { Botosan (1997), Eng } \\
\text { e Mak (2003) }\end{array}$ \\
FCSU & Fatores Críticos de Sucesso & Hail (2002) \\
ESTR & Estrutura Organizacional & Hail (2002), Eng e \\
& & Mak (2003) \\
RELA & Relatório de Atividades & Lanzanda (2004), \\
& Bhojraj (2004) \\
SUMA & Sumário dos Resultados Históricos & Eng e Mak (2003) \\
CCAP & Custos da atividade de captação de Recursos & Bhojraj (2004) \\
PINV & Políticas, Projetos e Investimentos & Eng e Mak (2003) \\
PROJ & Resultados e desempenhos projetados & Eng e Mak (2003), \\
& & Bhojraj \\
RECB & Evidenciação dos Recursos com finalidade exclusiva & Bhojraj (2004), Hail \\
& & (2002)
\end{tabular}

Fonte: dados da pesquisa.

O nível de disclosure da organização (DISC) é calculado pela razão entre a pontuação obtida pelo indicador de disclosure da organização (ID) e total de pontos possíveis (nesse caso, 20 pontos). Assim, o resultado dessa equação variará de $0 \%$ (ausência de todos os itens analisados) a $100 \%$ (presença de todos os itens analisados).

Assim, o indicador de disclosure da organização (ID) é calculado pela soma total de pontos entre os 10 itens obrigatórios (IO) e os 10 de divulgação voluntária (IV), conforme equação 1 , podendo variar da nota mínima (zero) até a máxima (20):

Equação (1) ID = IO + IV

\section{Resultados e Análises}

Como mencionado a princípio, a base amostral das OTS analisadas se referiu às 100 maiores instituições localizadas no Estado do Ceará coletadas junto ao site www.ongsbrasil.com.br. Com base no acesso às páginas $W e b$ respectivas, restaram 71 (sete $\mathrm{e}$ uma) unidades, dado que nem todas as participantes dispunham de dados que permitiram a extração das informações necessários (Tabela 3).

Esta tabela encontra-se organizada em função dos dados consolidados das entidades pesquisadas, em termos de informações obrigatórias (Grupo I) e voluntárias (Grupo II) disponibilizadas. O questionário aplicado possui um total de 20 perguntas, alocadas em 10 itens para cada conjunto de informações (voluntárias e obrigatórias), cujo somatório indica a escala de percentual logrado entre 0 a 50\% para cada grupo (I e II), representando o nível de disclosure (DISC). 
Tabela 3

a) Natureza das informações (obrigatórias e voluntárias) divulgadas pelas maiores OTS do Estado do Ceará

\begin{tabular}{|c|c|c|c|c|c|c|c|c|c|c|c|c|c|c|c|c|c|c|c|c|c|c|c|c|c|}
\hline \multirow{3}{*}{ ENTIDADES } & \multicolumn{12}{|c|}{ GRUPO I } & \multicolumn{12}{|c|}{ GRUPO II } & \multirow{3}{*}{$\begin{array}{c}\text { TOTAL } \\
\text { GERAL } \\
100 \% \\
(\% \mathrm{~A}+\mathrm{B})\end{array}$} \\
\hline & \multicolumn{12}{|c|}{ OBRIGATÓRIA (Mandatory Disclosure) - 10 pontos (50\%) } & \multicolumn{12}{|c|}{ VOLUNTÁRIA (Voluntary Disclosure) - 10 pontos (50\%) } & \\
\hline & DISP & PUBL & NOTA & SEGR & CRIT & ISEN & SUBV & OBLP & AUD & $\mathrm{CONV}$ & TOTAL & $(\%) \mathrm{A}$ & DMOM & SERV & FCSU & ESTR & RELA & SUMA & CCAP & PINV & PROJ & RECB & TOTAL & $(\%) \mathrm{B}$ & \\
\hline INC & 0 & 0 & 0 & 0 & 0 & 0 & 0 & 0 & 0 & 0 & 0 & $0 \%$ & 1 & 1 & 1 & 1 & 1 & 1 & 1 & 1 & 1 & 1 & 10 & $10 \%$ & $10 \%$ \\
\hline FEQ & 0 & 0 & 0 & 0 & 0 & 0 & 0 & 0 & 0 & 0 & 0 & $0 \%$ & 1 & 1 & 1 & 0 & 1 & 1 & 0 & 1 & 1 & 0 & 7 & $7 \%$ & $7 \%$ \\
\hline SCMS & 0 & 0 & 0 & 0 & 0 & 0 & 0 & 0 & 0 & 0 & 0 & $0 \%$ & 1 & 1 & 1 & 1 & 1 & 1 & 0 & 1 & 1 & 0 & 8 & $8 \%$ & $8 \%$ \\
\hline AIMC & 0 & 0 & 0 & 0 & 0 & 0 & 0 & 0 & 0 & 0 & 0 & $0 \%$ & 1 & 1 & 1 & 1 & 0 & 0 & 0 & 1 & 0 & 0 & 5 & $5 \%$ & $5 \%$ \\
\hline ICC & 0 & 0 & 0 & 0 & 0 & 0 & 0 & 0 & 0 & 0 & 0 & $0 \%$ & 1 & 1 & 1 & 1 & 0 & 0 & 0 & 1 & 0 & 0 & 5 & $5 \%$ & $5 \%$ \\
\hline ISCMF & 1 & 1 & 1 & 0 & 0 & 1 & 1 & 0 & 1 & 0 & 6 & $6 \%$ & 1 & 1 & 1 & 1 & 1 & 1 & 1 & 1 & 1 & 1 & 10 & $10 \%$ & $16 \%$ \\
\hline SAMEAC & 0 & 0 & 0 & 0 & 0 & 0 & 0 & 0 & 0 & 0 & 0 & $0 \%$ & 1 & 1 & 1 & 1 & 0 & 0 & 0 & 1 & 0 & 0 & 5 & $5 \%$ & $5 \%$ \\
\hline HMSVP & 0 & 0 & 0 & 0 & 0 & 0 & 0 & 0 & 0 & 0 & 0 & $0 \%$ & 1 & 1 & 1 & 1 & 0 & 0 & 0 & 1 & 0 & 0 & 5 & $5 \%$ & $5 \%$ \\
\hline IDSC & 0 & 0 & 0 & 0 & 0 & 0 & 0 & 0 & 0 & 0 & 0 & $0 \%$ & 1 & 1 & 1 & 0 & 0 & 0 & 0 & 0 & 0 & 0 & 3 & $3 \%$ & $3 \%$ \\
\hline AIAM & 0 & 0 & 0 & 0 & 0 & 0 & 0 & 0 & 0 & 0 & 0 & $0 \%$ & 1 & 0 & 1 & 0 & 0 & 0 & 0 & 0 & 0 & 0 & 2 & $2 \%$ & $2 \%$ \\
\hline $\mathrm{CSCA}$ & 0 & 0 & 0 & 0 & 0 & 0 & 0 & 0 & 0 & 0 & 0 & $0 \%$ & 0 & 0 & 0 & 0 & 0 & 0 & 0 & 0 & 0 & 0 & 0 & $0 \%$ & $0 \%$ \\
\hline AS & 0 & 0 & 0 & 0 & 0 & 0 & 0 & 0 & 0 & 0 & 0 & $0 \%$ & 1 & 1 & 1 & 0 & 0 & 0 & 0 & 1 & 0 & 0 & 4 & $4 \%$ & $4 \%$ \\
\hline CFSTJ & 0 & 0 & 0 & 0 & 0 & 0 & 0 & 0 & 0 & 0 & 0 & $0 \%$ & 0 & 1 & 1 & 1 & 0 & 0 & 0 & 1 & 0 & 0 & 4 & $4 \%$ & $4 \%$ \\
\hline CEJJP & 0 & 0 & 0 & 0 & 0 & 0 & 0 & 0 & 0 & 0 & 0 & $0 \%$ & 1 & 1 & 1 & 0 & 0 & 0 & 0 & 1 & 0 & 0 & 4 & $4 \%$ & $4 \%$ \\
\hline LACB & 0 & 0 & 0 & 0 & 0 & 0 & 0 & 0 & 0 & 0 & 0 & $0 \%$ & 1 & 1 & 1 & 0 & 0 & 0 & 0 & 1 & 0 & 0 & 4 & $4 \%$ & $4 \%$ \\
\hline SHFC & 0 & 0 & 0 & 0 & 0 & 0 & 0 & 0 & 0 & 0 & 0 & $0 \%$ & 0 & 1 & 0 & 0 & 0 & 0 & 1 & 0 & 0 & 0 & 2 & $2 \%$ & $2 \%$ \\
\hline FAL & 0 & 0 & 0 & 0 & 0 & 0 & 0 & 0 & 0 & 0 & 0 & $0 \%$ & 0 & 1 & 1 & 0 & 0 & 0 & 0 & 1 & 0 & 0 & 3 & $3 \%$ & $3 \%$ \\
\hline FOCS & 0 & 0 & 0 & 0 & 0 & 0 & 0 & 0 & 0 & 0 & 0 & $0 \%$ & 1 & 1 & 0 & 1 & 0 & 0 & 0 & 0 & 0 & 0 & 3 & $3 \%$ & $3 \%$ \\
\hline IENL & 0 & 0 & 0 & 0 & 0 & 0 & 0 & 0 & 0 & 0 & 0 & $0 \%$ & 1 & 1 & 1 & 1 & 0 & 0 & 1 & 1 & 1 & 0 & 7 & $7 \%$ & $7 \%$ \\
\hline IAPS & 0 & 0 & 0 & 0 & 0 & 0 & 0 & 0 & 0 & 0 & 0 & $0 \%$ & 1 & 1 & 1 & 1 & 0 & 0 & 0 & 1 & 0 & 0 & 5 & $5 \%$ & $5 \%$ \\
\hline SQPA & 0 & 0 & 0 & 0 & 0 & 0 & 0 & 0 & 0 & 0 & 0 & $0 \%$ & 1 & 1 & 1 & 1 & 0 & 0 & 0 & 1 & 0 & 0 & 5 & $5 \%$ & $5 \%$ \\
\hline CNSG & 0 & 0 & 0 & 0 & 0 & 0 & 0 & 0 & 0 & 0 & 0 & $0 \%$ & 1 & 0 & 0 & 0 & 0 & 0 & 0 & 0 & 0 & 0 & 1 & $1 \%$ & $1 \%$ \\
\hline
\end{tabular}

Fonte: adaptado de www.ongsbrasil.com.br 
b) CONTINUAÇÃO - Natureza das informações (obrigatórias e voluntárias) divulgadas pelas maiores OTS do Ceará

\begin{tabular}{|c|c|c|c|c|c|c|c|c|c|c|c|c|c|c|c|c|c|c|c|c|c|c|c|c|c|}
\hline \multirow{3}{*}{ ENTIDADES } & \multicolumn{12}{|c|}{ GRUPO I } & \multicolumn{12}{|c|}{ GRUPO II } & \multirow{3}{*}{$\begin{array}{c}\text { TOTAL } \\
\text { GERAL } \\
100 \% \\
(\% \mathrm{~A}+\mathrm{B})\end{array}$} \\
\hline & \multicolumn{12}{|c|}{ OBRIGATÓRIA (Mandatory Disclosure) - 10 pontos (50\%) } & \multicolumn{12}{|c|}{ VOLUNTÁRIA (Voluntary Disclosure) - 10 pontos (50\%) } & \\
\hline & DISP & PUBL & NOTA & SEGR & CRIT & ISEN & SUBV & OBLP & AUD & CONV & TOTAL & $(\%) \mathrm{A}$ & DMOM & SERV & FCSU & ESTR & RELA & SUMA & CCAP & PINV & PROJ & RECB & TOTAL & $(\%) \mathrm{B}$ & \\
\hline $\mathrm{CJC}$ & 0 & 0 & 0 & 0 & 0 & 0 & 0 & 0 & 0 & 0 & 0 & $0 \%$ & 1 & 0 & 0 & 0 & 0 & 0 & 0 & 0 & 0 & 0 & 1 & $1 \%$ & $1 \%$ \\
\hline ADES & 1 & 1 & 0 & 1 & 0 & 0 & 0 & 0 & 0 & 1 & 4 & $4 \%$ & 1 & 1 & 1 & 1 & 1 & 1 & 1 & 1 & 0 & 1 & 9 & $9 \%$ & $13 \%$ \\
\hline AMCP & 0 & 0 & 0 & 0 & 0 & 0 & 0 & 0 & 0 & 0 & 0 & $0 \%$ & 1 & 1 & 0 & 1 & 0 & 0 & 0 & 1 & 0 & 0 & 4 & $4 \%$ & $4 \%$ \\
\hline IPDE & 0 & 0 & 0 & 0 & 0 & 0 & 0 & 0 & 0 & 0 & 0 & $0 \%$ & 1 & 1 & 1 & 1 & 0 & 0 & 0 & 1 & 0 & 0 & 5 & $5 \%$ & $5 \%$ \\
\hline RPPA & 0 & 0 & 0 & 0 & 0 & 0 & 0 & 0 & 0 & 0 & 0 & $0 \%$ & 1 & 1 & 1 & 0 & 0 & 0 & 0 & 1 & 0 & 0 & 4 & $4 \%$ & $4 \%$ \\
\hline CSI & 0 & 0 & 0 & 0 & 0 & 0 & 0 & 0 & 0 & 0 & 0 & $0 \%$ & 0 & 0 & 0 & 0 & 0 & 0 & 0 & 0 & 0 & 0 & 0 & $0 \%$ & $0 \%$ \\
\hline LTM & 0 & 0 & 0 & 0 & 0 & 0 & 0 & 0 & 0 & 0 & 0 & $0 \%$ & 1 & 1 & 1 & 1 & 0 & 0 & 1 & 1 & 0 & 0 & 6 & $6 \%$ & $6 \%$ \\
\hline ABMP & 0 & 0 & 0 & 0 & 0 & 0 & 0 & 0 & 0 & 0 & 0 & $0 \%$ & 0 & 1 & 0 & 0 & 1 & 0 & 0 & 1 & 0 & 0 & 3 & $3 \%$ & $3 \%$ \\
\hline $\mathrm{ACC}$ & 0 & 0 & 0 & 0 & 0 & 0 & 0 & 0 & 0 & 0 & 0 & $0 \%$ & 1 & 1 & 1 & 0 & 0 & 1 & 1 & 1 & 0 & 0 & 6 & $6 \%$ & $6 \%$ \\
\hline AQEV & 0 & 0 & 0 & 0 & 0 & 0 & 0 & 0 & 0 & 0 & 0 & $0 \%$ & 1 & 1 & 1 & 0 & 0 & 0 & 0 & 1 & 0 & 0 & 4 & $4 \%$ & $4 \%$ \\
\hline UECI & 0 & 0 & 0 & 0 & 0 & 0 & 0 & 0 & 0 & 0 & 0 & $0 \%$ & 1 & 1 & 1 & 0 & 0 & 0 & 0 & 1 & 0 & 0 & 4 & $4 \%$ & $4 \%$ \\
\hline CPSF & 0 & 0 & 0 & 0 & 0 & 0 & 0 & 0 & 0 & 0 & 0 & $0 \%$ & 1 & 0 & 1 & 1 & 0 & 0 & 0 & 0 & 0 & 0 & 3 & $3 \%$ & $3 \%$ \\
\hline IMS & 1 & 1 & 0 & 1 & 0 & 0 & 0 & 0 & 0 & 0 & 3 & $3 \%$ & 1 & 1 & 1 & 1 & 1 & 1 & 0 & 1 & 0 & 0 & 7 & $7 \%$ & $10 \%$ \\
\hline IWF & 0 & 0 & 0 & 0 & 0 & 0 & 0 & 0 & 0 & 0 & 0 & $0 \%$ & 1 & 0 & 1 & 1 & 0 & 0 & 0 & 0 & 0 & 0 & 3 & $3 \%$ & $3 \%$ \\
\hline APSM & 0 & 0 & 0 & 0 & 0 & 0 & 0 & 0 & 0 & 0 & 0 & $0 \%$ & 1 & 0 & 0 & 0 & 0 & 0 & 0 & 0 & 0 & 0 & 1 & $1 \%$ & $1 \%$ \\
\hline SAC & 0 & 0 & 0 & 0 & 0 & 0 & 0 & 0 & 0 & 0 & 0 & $0 \%$ & 1 & 1 & 0 & 1 & 0 & 0 & 0 & 0 & 0 & 0 & 3 & $3 \%$ & $3 \%$ \\
\hline ISJ & 0 & 0 & 0 & 0 & 0 & 0 & 0 & 0 & 0 & 0 & 0 & $0 \%$ & 1 & 1 & 0 & 1 & 0 & 0 & 0 & 1 & 0 & 0 & 4 & $4 \%$ & $4 \%$ \\
\hline ABPN & 0 & 0 & 0 & 0 & 0 & 0 & 0 & 0 & 0 & 0 & 0 & $0 \%$ & 1 & 1 & 1 & 1 & 0 & 0 & 0 & 1 & 0 & 0 & 5 & $5 \%$ & $5 \%$ \\
\hline CVP & 0 & 0 & 0 & 0 & 0 & 0 & 0 & 0 & 0 & 0 & 0 & $0 \%$ & 1 & 1 & 1 & 0 & 0 & 0 & 0 & 1 & 0 & 0 & 4 & $4 \%$ & $4 \%$ \\
\hline AAN & 0 & 0 & 0 & 0 & 0 & 0 & 0 & 0 & 0 & 0 & 0 & $0 \%$ & 0 & 0 & 0 & 0 & 0 & 0 & 0 & 0 & 0 & 0 & 0 & $0 \%$ & $0 \%$ \\
\hline APAE & 0 & 0 & 0 & 0 & 0 & 0 & 0 & 0 & 0 & 0 & 0 & $0 \%$ & 1 & 1 & 1 & 0 & 0 & 0 & 0 & 1 & 0 & 0 & 4 & $4 \%$ & $4 \%$ \\
\hline PSC & 0 & 0 & 0 & 0 & 0 & 0 & 0 & 0 & 0 & 0 & 0 & $0 \%$ & 1 & 1 & 1 & 1 & 0 & 0 & 0 & 0 & 0 & 0 & 4 & $4 \%$ & $4 \%$ \\
\hline AAEI & 0 & 0 & 0 & 0 & 0 & 0 & 0 & 0 & 0 & 0 & 0 & $0 \%$ & 1 & 1 & 1 & 1 & 0 & 0 & 0 & 0 & 0 & 0 & 4 & $4 \%$ & $4 \%$ \\
\hline \multicolumn{26}{|c|}{ Fonte: adaptado de www.ongsbrasil.com.br } \\
\hline
\end{tabular}


c) CONTINUAÇÃO - Natureza das informações (obrigatórias e voluntárias) divulgadas pelas maiores OTS do Ceará

\begin{tabular}{|c|c|c|c|c|c|c|c|c|c|c|c|c|c|c|c|c|c|c|c|c|c|c|c|c|c|}
\hline \multirow{3}{*}{ ENTIDADES } & \multicolumn{12}{|c|}{ GRUPO I } & \multicolumn{12}{|c|}{ GRUPO II } & \multirow{3}{*}{$\begin{array}{c}\text { TOTAI } \\
\text { GERAI } \\
\mathbf{1 0 0} \% \\
(\% \mathrm{~A}+\mathrm{B})\end{array}$} \\
\hline & \multicolumn{12}{|c|}{ OBRIGATÓRIA (Mandatory Disclosure) - 10 pontos (50\%) } & \multicolumn{12}{|c|}{ VOLUNTÁRIA (Voluntary Disclosure) - 10 pontos (50\%) } & \\
\hline & DISP & PUBL & NOTA & SEGR & CRIT & ISEN & SUBV & OBLP & AUD & CONV & TOTAL & $(\%) \mathrm{A}$ & $\begin{array}{l}\text { DMOM } \\
\end{array}$ & SERV & FCSU & ESTR & RELA & SUMA & CCAP & PINV & PROJ & RECB & TOTAL & $(\%) \mathrm{B}$ & \\
\hline INSA & 0 & 0 & 0 & 0 & 0 & 0 & 0 & 0 & 0 & 0 & 0 & $0 \%$ & 1 & 1 & 1 & 0 & 0 & 0 & 0 & 0 & 0 & 0 & 3 & $3 \%$ & $3 \%$ \\
\hline AVPF & 0 & 0 & 0 & 0 & 0 & 0 & 0 & 0 & 0 & 0 & 0 & $0 \%$ & 1 & 1 & 1 & 1 & 0 & 0 & 0 & 0 & 0 & 0 & 4 & $4 \%$ & $4 \%$ \\
\hline IMA & 0 & 0 & 0 & 0 & 0 & 0 & 0 & 0 & 0 & 0 & 0 & $0 \%$ & 1 & 1 & 1 & 0 & 0 & 0 & 0 & 0 & 0 & 0 & 3 & $3 \%$ & $3 \%$ \\
\hline OFAJ & 0 & 0 & 0 & 0 & 0 & 0 & 0 & 0 & 0 & 0 & 0 & $0 \%$ & 1 & 1 & 0 & 0 & 0 & 0 & 0 & 0 & 0 & 0 & 2 & $2 \%$ & $2 \%$ \\
\hline $\mathrm{AH}$ & 0 & 0 & 0 & 0 & 0 & 0 & 0 & 0 & 0 & 0 & 0 & $0 \%$ & 1 & 1 & 1 & 0 & 0 & 0 & 0 & 1 & 0 & 0 & 4 & $4 \%$ & $4 \%$ \\
\hline AAEC & 0 & 0 & 0 & 0 & 0 & 0 & 0 & 0 & 0 & 0 & 0 & $0 \%$ & 1 & 1 & 1 & 1 & 0 & 0 & 0 & 0 & 0 & 0 & 4 & $4 \%$ & $4 \%$ \\
\hline APAE & 0 & 0 & 0 & 0 & 0 & 0 & 0 & 0 & 0 & 0 & 0 & $0 \%$ & 1 & 1 & 1 & 0 & 0 & 0 & 0 & 1 & 0 & 0 & 4 & $4 \%$ & $4 \%$ \\
\hline ESR & 0 & 0 & 0 & 0 & 0 & 0 & 0 & 0 & 0 & 0 & 0 & $0 \%$ & 0 & 1 & 1 & 1 & 0 & 0 & 0 & 0 & 0 & 0 & 3 & $3 \%$ & $3 \%$ \\
\hline PSJ & 0 & 0 & 0 & 0 & 0 & 0 & 0 & 0 & 0 & 0 & 0 & $0 \%$ & 1 & 1 & 1 & 1 & 0 & 0 & 0 & 0 & 0 & 0 & 4 & $4 \%$ & $4 \%$ \\
\hline CEBS & 0 & 0 & 0 & 0 & 0 & 0 & 0 & 0 & 0 & 0 & 0 & $0 \%$ & 0 & 0 & 1 & 1 & 0 & 0 & 0 & 0 & 0 & 0 & 2 & $2 \%$ & $2 \%$ \\
\hline ITIC & 0 & 0 & 0 & 0 & 0 & 0 & 0 & 0 & 0 & 0 & 0 & $0 \%$ & 1 & 1 & 0 & 0 & 0 & 0 & 0 & 1 & 0 & 0 & 3 & $3 \%$ & $3 \%$ \\
\hline EDISCA & 0 & 0 & 0 & 0 & 0 & 0 & 0 & 0 & 0 & 0 & 0 & $0 \%$ & 1 & 1 & 1 & 0 & 0 & 0 & 0 & 0 & 0 & 0 & 3 & $3 \%$ & $3 \%$ \\
\hline DJC & 0 & 0 & 0 & 0 & 0 & 0 & 0 & 0 & 0 & 0 & 0 & $0 \%$ & 1 & 1 & 1 & 0 & 0 & 0 & 0 & 0 & 0 & 0 & 3 & $3 \%$ & $3 \%$ \\
\hline $\mathrm{AC}$ & 0 & 0 & 0 & 0 & 0 & 0 & 0 & 0 & 0 & 0 & 0 & $0 \%$ & 1 & 1 & 0 & 0 & 0 & 0 & 0 & 0 & 0 & 0 & 2 & $2 \%$ & $2 \%$ \\
\hline ACAA & 0 & 0 & 0 & 0 & 0 & 0 & 0 & 0 & 0 & 0 & 0 & $0 \%$ & 1 & 1 & 1 & 0 & 0 & 0 & 0 & 1 & 0 & 0 & 4 & $4 \%$ & $4 \%$ \\
\hline LCSB & 0 & 0 & 0 & 0 & 0 & 0 & 0 & 0 & 0 & 0 & 0 & $0 \%$ & 1 & 1 & 1 & 1 & 0 & 0 & 0 & 0 & 0 & 0 & 4 & $4 \%$ & $4 \%$ \\
\hline AAEM & 0 & 0 & 0 & 0 & 0 & 0 & 0 & 0 & 0 & 0 & 0 & $0 \%$ & 0 & 0 & 1 & 0 & 0 & 0 & 0 & 1 & 0 & 0 & 2 & $2 \%$ & $2 \%$ \\
\hline AMEV & 0 & 0 & 0 & 0 & 0 & 0 & 0 & 0 & 0 & 0 & 0 & $0 \%$ & 0 & 0 & 1 & 0 & 0 & 0 & 0 & 1 & 0 & 0 & 2 & $2 \%$ & $2 \%$ \\
\hline $\mathrm{ABA}$ & 0 & 0 & 0 & 0 & 0 & 0 & 0 & 0 & 0 & 0 & 0 & $0 \%$ & 1 & 1 & 1 & 0 & 0 & 0 & 0 & 1 & 0 & 0 & 4 & $4 \%$ & $4 \%$ \\
\hline $\mathrm{ABOC}$ & 0 & 0 & 0 & 0 & 0 & 0 & 0 & 0 & 0 & 0 & 0 & $0 \%$ & 1 & 1 & 1 & 1 & 0 & 0 & 0 & 1 & 0 & 0 & 5 & $5 \%$ & $5 \%$ \\
\hline IDTS & 0 & 0 & 0 & 0 & 0 & 0 & 0 & 0 & 0 & 0 & 0 & $0 \%$ & 1 & 1 & 1 & 1 & 1 & 0 & 0 & 1 & 0 & 0 & 6 & $6 \%$ & $6 \%$ \\
\hline SHD & 0 & 0 & 0 & 0 & 0 & 0 & 0 & 0 & 0 & 0 & 0 & $0 \%$ & 1 & 0 & 1 & 0 & 0 & 0 & 1 & 0 & 0 & 0 & 3 & $3 \%$ & $3 \%$ \\
\hline
\end{tabular}

Fonte: adaptado de www.ongsbrasil.com.br 
d) CONTINUAÇÃO - Natureza das informações (obrigatórias e voluntárias) divulgadas pelas maiores OTS do Ceará

\begin{tabular}{|c|c|c|c|c|c|c|c|c|c|c|c|c|c|c|c|c|c|c|c|c|c|c|c|c|c|}
\hline \multirow{3}{*}{ ENTIDADES } & \multicolumn{12}{|c|}{ GRUPO I } & \multicolumn{12}{|c|}{ GRUPO II } & \multirow{3}{*}{$\begin{array}{c}\text { TOTAL } \\
\text { GERAL } \\
100 \% \\
(\% \mathrm{~A}+\mathrm{B})\end{array}$} \\
\hline & \multicolumn{12}{|c|}{ OBRIGATÓRIA (Mandatory Disclosure) - 10 pontos (50\%) } & \multicolumn{12}{|c|}{ VOLUNTÁRIA (Voluntary Disclosure) - 10 pontos (50\%) } & \\
\hline & DISP & PUBL & NOTA & SEGR & CRIT & ISEN & SUBV & OBLP & AUD & CONV & TOTAL & $(\%) \mathrm{A}$ & DMOM & SERV & FCSU & ESTR & RELA & SUMA & CCAP & PINV & PROJ & RECB & TOTAL & $(\%) \mathrm{B}$ & \\
\hline CJDB & 0 & 0 & 0 & 0 & 0 & 0 & 0 & 0 & 0 & 0 & 0 & $0 \%$ & 1 & 1 & 1 & 0 & 0 & 0 & 0 & 0 & 0 & 0 & 3 & $3 \%$ & $3 \%$ \\
\hline AFAI & 0 & 0 & 0 & 0 & 0 & 0 & 0 & 0 & 0 & 0 & 0 & $0 \%$ & 1 & 1 & 1 & 0 & 0 & 0 & 0 & 0 & 0 & 0 & 3 & $3 \%$ & $3 \%$ \\
\hline CEPD & 0 & 0 & 0 & 0 & 0 & 0 & 0 & 0 & 0 & 0 & 0 & $0 \%$ & 0 & 0 & 1 & 0 & 0 & 0 & 0 & 1 & 0 & 0 & 2 & $2 \%$ & $2 \%$ \\
\hline FIC & 0 & 0 & 0 & 0 & 0 & 0 & 0 & 0 & 0 & 0 & 0 & $0 \%$ & 1 & 0 & 1 & 0 & 0 & 0 & 0 & 0 & 0 & 0 & 2 & $2 \%$ & $2 \%$ \\
\hline TOTAL & 3 & 3 & 1 & 2 & 0 & 1 & 1 & 0 & 1 & 1 & 13 & $2 \%$ & 59 & 56 & 56 & 32 & 8 & 7 & 8 & 40 & 5 & 3 & 274 & $39 \%$ & $41 \%$ \\
\hline (\%) & $4 \%$ & $4 \%$ & $1 \%$ & $3 \%$ & $0 \%$ & $1 \%$ & $1 \%$ & $0 \%$ & $1 \%$ & $1 \%$ & $2 \%$ & & $83 \%$ & $79 \%$ & $79 \%$ & $45 \%$ & $11 \%$ & $10 \%$ & $11 \%$ & $56 \%$ & $7 \%$ & $4 \%$ & $39 \%$ & & \\
\hline
\end{tabular}

Fonte: adaptado de www.ongsbrasil.com.br 
O Grupo I trata das informações obrigatórias (IO), tais como: disponibilização de demonstrações contábeis, notas explicativas, procedimentos específicos para detalhamento das receitas e despesas, montante de subvenções recebidas, realização de auditorias independentes etc. selecionadas a partir de critérios adotados nas normas brasileiras de contabilidade que tratam do assunto. Os resultados, ao contrário do que se esperavam, revelaram baixo nível de disclosure das informações requeridas atingindo um percentual de $2 \%$ de um total de $50 \%$ esperados (10 pontos), sobressaindo-se: publicação das demonstrações contábeis no próprio site e perante à imprensa oficial ou privada (DISP e PUBL 4\%) e segregação de contas de receitas e despesas (SEGR 3\%).

De maneira geral, os resultados foram considerados insatisfatórios, chamando atenção as variáveis que não obtiveram nenhuma pontuação no grupo das 71 organizações pesquisadas: informações sobre os critérios de apuração das receitas e despesas (CRIT) e descrição das condições (taxas, prazos etc.) das obrigações de longo prazo (OBLP). O descumprimento representa uma grave irregularidade devido ao caráter impositivo das informações que são exigidas dos gestores, revelando que praticamente quase todas as entidades não apresentaram esse tipo de informação.

O maior percentual por entidade alcançado foi de $6 \%$ e quase a totalidade das OTS não evidenciou nenhuma das variáveis representativas do disclosure obrigatório. Situação deveras preocupante, visto que representa um comportamento homogêneo e de descompromisso com a norma legal, principalmente no que referente às informações financeiras básicas: demonstrações contábeis, notas explicativas, divulgação de receitas e despesas. Como todas as variáveis obrigatórias são de origem contábil, uma possível explicação para o resultado advém da pouca importância atribuída à Contabilidade por parte dos executivos destas organizações e quiçá a falta de compreensão dela como instrumento de gestão e avaliação das pontuações alcançadas.

Cabe observar que nas entidades componentes do terceiro setor são várias as dificuldades na elaboração e apresentação das informações contábeis. Dentre essas dificuldades, pode-se citar: a própria natureza dos serviços que prestam e a escassez de recursos com que trabalham, e ainda, na maioria das vezes, o fato de a organização primar pela informalidade, praticamente sem normas e procedimentos escritos, gerando comportamentos tendentes à falta de controle e aplicação dos recursos doados.

Não obstante tais empecilhos sejam justificados, não são aceitáveis. Ao contrário, pelo fato de prestarem contas a doadores, financiadores e patrocinadores é que as OTS deveriam ser mais responsivas, evidenciar resultados e demonstrar com clareza e transparência sua posição econômica, financeira e social.

Aliado a isto, não se tem notícia da aplicação de sanções às OTS pela inobservância das normas legais, o que poderia minimizar o descumprimento das normas editadas. Portanto, os resultados dos componentes do disclosure obrigatório apontam para o fortalecimento da assimetria de informação, justamente o que deveria impedir.

O Grupo II trata das informações voluntárias, tais como: serviço prestados, relatório de atividades, políticas, projetos e investimentos etc. tendo os resultados revelado situação mais favorável (39\% dos 50\% previstos) quando comparada ao grupo de informações obrigatórias (Grupo I - 2\%). Entre as variáveis que lograram melhor pontuação, encontram-se a declaração de metas, objetivos e missão da organização (DMOM, 83\%), descrição de serviços prestados (SERV, 79\%) e fatores críticos de sucesso (FCSU, 79\%). Por sua vez, as variáveis com menor percentual, foram representadas pelos itens desempenhos projetados (PROJ, 7\%) e evidenciação dos recursos com finalidade exclusiva (RECB, 4\%).

De longe, nota-se o desempenho superior do disclosure voluntário comparado ao obrigatório, tanto em relação aos resultados individuais, geral e quantidade de variáveis que melhor pontuaram. Embora seja uma disfunção de ordem gerencial, este resultado não se 
apresenta tão grave quanto o primeiro. Ao contrário, apresenta-se melhor posicionado que o disclosure obrigatório, corroborando a tendência mundial em se ampliar esse tipo de informação, inclusive através da utilização de canais tecnológicos, como o chamado $e$ disclosure (Lee, \& Joseph, 2013, Gajewski, \& Li, 2015).

Como se mencionou na revisão da literatura, as informações voluntárias representam parcela do poder discricionário dos gestores das OTS, deixando nas entrelinhas que a escolha realizada depende dos custos e dos benefícios associados. Diversos autores aspectos como: governança corporativa (Ho \& Wong, 2001), desempenho sustentável (khan, Serafeim, \& Yoon, 2016, Ng, \& Rezaee, 2015) e conhecimentos prévios dos executivos (Bamber, Jiang, \& Wang, 2010).

Se por um lado as OTS se dedicam a difundir mais declaração de metas, objetivos e missão da organização, descrição dos serviços prestados, fatores críticos de sucesso e políticas, projetos/investimentos e organograma, por outro, optam em não divulgar tanto o andamento de atividades (RELA 11\%), formas de captação de recursos (CCAP, 11\%), informações sobre desempenho (PROJ, 7\%), doações (RECB, 4\%) e informações históricas (SUMA, 10\%). Isto demonstra que nem sempre essas organizações têm uma ideia clara de sua missão, de forma a delimitar suas ações e metas, o que dificulta a avaliação dos resultados.

Daí se observar que prevalece a informalidade, havendo poucas normas e procedimentos escritos, o que as torna ágeis, mas dificulta a gestão. Dito de outra forma: operando em um ambiente desfavorável, caracterizado por falta de recursos e de apoio do poder público, as OTS não conseguem romper o círculo vicioso em que se encontram referente à falta de recursos humanos e financeiros adequados com vistas a atingir seus objetivos.

Em relação aos Grupos I e II, no seu conjunto, é evidente o não compartilhamento de informações essenciais de natureza contábil, enquanto que outras de fácil localização ou que não possibilitam uma efetiva avaliação da gestão das entidades - de caráter orçamental -, são divulgadas. Esta conclusão é condizente com Tenório (2004) que destaca elevado grau de compartilhamento das atividades (voluntárias), embora haja pouca sistematização dos dados para efeito de avaliação do desempenho (obrigatórias).

Comparando-se os resultados, não mais em termos de ambos os grupos, porém entre as entidades da amostra, é de se notar que as únicas entidades que pontuaram em termos de informações obrigatórias foram as mesmas que obtiveram os valores mais altos no disclosure voluntário. Com base nisto, os resultados das OTS cearenses chamam atenção em virtude da natureza das informações que deveriam ser divulgadas e não foram. Primeiro, em razão do descumprimento do normativo legal (NBC T 11 e ITG 2002), ao quais se encontram vinculadas as OTS. Segundo, face a inversão de pontuação entre os coeficientes de informação obrigatória e voluntária, que se esperava houvesse uma adesão integral em referência aos coeficientes de ordem obrigatória e satisfatória no tocante aos voluntários.

A transparência e a accountability são pressupostos básicos das organizações, não somente às integrantes do setor público, como também da iniciativa privada. Entendem Saxton, Kuo e Ho (2011) que tanto a accountability como a transparência são necessárias para manter a confiança nas organizações sem finalidade lucrativa, bem como este último atributo é capaz de diminuir a assimetria informacional.

Em relação às entidades estudadas, tais características desempenham um papel maior em virtude dos serviços que prestam, do aporte de recursos públicos provenientes da Administração Pública e/ou recebidos por doações. Assim, tanto um como outro aspecto podem e devem ser analisados isoladamente com base em cada modalidade de disclosure (obrigatório e voluntário). 


\section{Considerações Finais}

O presente trabalho avaliou o nível de disclosure das organizações do terceiro setor sediadas no Estado do Ceará em um total de 100 entidades. Sabe-se que as organizações não governamentais são responsáveis por dois aspectos chaves de acccountability: finanças e desempenho.

A pesquisa foi seccionada em 2 grandes grupos - informações obrigatórias (Grupo I) e voluntárias (Grupo II) - e tinha por objetivo avaliar o disclosure de ambos os grupos mediante comparação de critérios pré-selecionados com base em normas do CFC e revisão da literatura internacional, mediante a formação de um indicador de divulgação que permitiria aferir o nível de informação destas organizações.

Utilizou-se como pressuposto que a transparência seria capaz de diminuir a assimetria de informação, base da Teoria da Agência. Logo, haveria uma tendência natural que as OTS se sentissem motivadas a ampliar seu escopo de informação, devido a própria natureza das atividades que desempenham, reforçando o atributo accountability, tão importante para elas.

Realizada a coletada de dados, evidenciou-se que tanto a transparência como o processo de accountability destas instituições se encontram prejudicados. Os maiores percentuais do Grupo I (informações obrigatórias) foram na ordem de 6\%, enquanto que a pontuação por critério chegou a $4 \%$. Considerando todas as entidades com resultados analisados (71 OTS), a divulgação chegou a $2 \%$ dos 10 pontos definidos para o grupo.

Embora todos indicadores tenham pontuado de forma insatisfatória, a melhor pontuação ocorreu por parte da existência e divulgação das demonstrações contábeis (DISP e PUBL, ambos com 4\%) e aqueles que não obtiveram nenhuma pontuação foram os indicadores que trataram sobre os critérios de reconhecimento de receitas/despesas (CRIT) e disposição das condições das obrigações de longo prazo (OBLP). Entende-se que tais indicadores poderiam ter uma avaliação mais positiva caso o descumprimento gerasse algum tipo de sanção ou o não acesso a recursos de ordem pública.

O Grupo II (informações voluntárias) apresentou resultados mais favoráveis. Entre as entidades, $11 \%$ e, por critério, chegou-se a $83 \%$. Considerando todas as entidades deste grupo, a divulgação chegou a $39 \%$ dos 10 pontos máximos definidos para o grupo.

As informações voluntárias cujos resultados foram satisfatórios escondem uma realidade não facilmente evidenciada. Divulga-se somente as informações de mais fácil acesso, tais como declaração de metas, objetivos e missão da organização, descrição dos serviços prestados, fatores críticos de sucesso e políticas, projetos/investimentos e organograma, em prejuízo de outras - andamento de atividades (RELA), formas de captação de recursos (CCAP, 11\%), informações sobre desempenho (PROJ, 7\%), doações (RECB, 4\%) e informações históricas (SUMA, 10\%) que deveriam gozar de idêntico privilégio. Uma possível explicação para esta conduta se refere ao poder de escolha dos executivos sobre que informação divulgar.

De maneira geral, a situação é preocupante, notadamente quanto às informações de caráter obrigatório. Primeiro, porque decorre de norma contábil descumprida e não se observa nenhuma ação no sentido a fomentar o cumprimento; segundo, em razão de qualquer percentual abaixo dos $50 \%$ previstos (10 pontos) para o grupo I, por si só, já seria ilegal.

Avalia-se que esses resultados se mostraram contraditórios na medida que as entidades por não disporem de um aporte fixo de capitais, naturalmente se valem de fontes externas para prover as suas necessidades. Por outro lado, ao invés de se tornarem mais transparentes e solícitas com vista a prestarem contas das suas ações, assumem conduta justamente contrária. Os resultados demonstram ainda que há uma tendência entre as entidades de se manterem 
coerentes quanto às pontuações auferidas, percebendo-se que as mesmas informações que pontuaram sob os critérios de informação obrigatória foram as mesmas que se destacaram frente ao disclosure voluntário.

Em síntese, o estudo evidencia que o nível de disclosure das OTS do Estado do Ceará foi considerado insatisfatório, na medida que as informações obrigatórias e voluntárias totalizaram um percentual de $41 \%$ dos itens pesquisados.

Propõe-se que para trabalhos futuros adotem-se os critérios aqui definidos e amplie-se a amostra para todos os Estados da federação, dado que o cenário verificado no Estado do Ceará pode ser o mesmo para todo o país, o que ensejará a adoção de medidas urgentes visando à ampliação no nível de transparência e accountability.

\section{Referências}

Araújo, L. C. V. (2016). Auditoria em Organizações do Terceiro Setor. Universidade Federal do Ceará. 2008. Recuperado de: http://www.acep.org.br/proaudi/gapa.pdf.

Amagoh, F. (2015). Improving the credibility and effectiveness of non-governmental organizations. Progress in Development Studies, vol. 15, n. 3, p. 221-239.

Bolívar, M. P. R., Pérez, C. C., \& Hernández, A. M. L. (2006). Cultural contexts and governmental digital reporting. International Review of Administrative Sciences, vol. 72, n. 2 , p. 269-290.

Bamber, L. S., Jiang, J., \& Wang, I. Y. (2010). What's my style? The influence of top managers on voluntary corporate financial disclosure. The Accounting Review, vol. 85, n. 4, p. $1131-1162$.

Beattie, V. McInnes, B., \& Fearnley, S. (2004). A Methodology for Analysing and Evaluating Narratives in Annual Report: A Comprehensive Descriptive Profile and Metrics for Disclosure Quality Attributes, Accounting Forum, vol.28, n. 3, p. 205-236.

Beyer, A., Cohen, D. A., Lys, T. Z., \& Walther, B. R. (2010). The financial reporting environment: Review of the recent literature. Journal of Accounting and Economics, vol. 50, p. 296-343.

Bhojraj, S., Blacconiere, W. G., \& D’Souza, J. D. (2004). Voluntary disclosure in a multiaudience setting: an empirical analysis. The Accounting Review, vol. 79, n. 4, p. 921-947.

Cabedo, J. D., Fuertes-Fuertes, I., Maset-LLaudes, A., \& Tirado-Beltrán, J. M. (2017). Improving and measuring transparency in NGOs: A disclosure index for activities and projects. Nonprofit Management and Leadership, p. 1-10.

Christensen, A. L., \& Mohr, R. M. (2003). Not-for-profit annual reports: What do museum managers communicate? Financial Accountability \& Management, vol. 19, n. 2, 139-158

Charumathi, B., \& Ramesh, L. (2015). On the Determinants of Voluntary Disclosure by Indian Companies. Asia-Pacif Journal of Management Research and Innovation, vol. 11, n. 2, 2015 .

Conselho Federal de Contabilidade. (2016). NBC T 10.19: entidade sem finalidade de lucro. 2000. Recuperado de:

http://www.cfc.org.br/sisweb/sre/detalhes_sre.aspx?Codigo=2000/000877. 
Core, J. E. (2001). A Review of the Empirical Disclosure Literature: Discussion. Journal of Accounting and Economics, vol. 31, p. 441-456.

Crozatti, J., Cordeiro, A. A. L., \& Campos, P. A. C. (2006). Efeitos da falta de evidenciação nas demonstrações contábeis publicadas para determinação e análise do ciclo operacional e financeiro pelo usuário externo. Anais do Congresso USP de Controladoria e Contabilidade, São Paulo, SP, Brasil, 6, julho.

Dhaliwal, D. S., Li, O. Z., Tsang, A., \& Yang, Y. G. (2011). Voluntary non-financial disclosure and cost of equity capital: The initiation of corporate social responsibility reporting. The Accounting Review, 86, n. 1, p. 59-100.

Dye, R. A. (1985). Disclosure of nonproprietary information. Journal of Accounting Research, 23(1), 123-145.

Eng, L. L., \& Mak, Y. T. (2003). Corporate governance and voluntary disclosure. Journal of Accounting and Public Policy, n. 22, p. 325-345.

Ettredge, M., Richardson, V. J., \& Scholz, S. (2002). Dissemination of information for investors at corporate Web sites. Journal of Accounting and Public Policy, 21, n. 4-5, 357369.

Fernandes, R. C. (2002). Privado, porém público: o terceiro setor na América do Sul. Rio de Janeiro: Civicus.

Fick, K. (2010). The value of good corporate disclosure. The CPA Journal, vol. 80, n. 10, p. $40-42$.

Financial Accounting Standards Board (FASB), 2014. Recuperado de:

http://www.fasb.org/cs/ContentServer?c=Document_C\&cid=1176164329772\&d=\&pagename $=$ FASB $\% 2$ FDocument C $\% 2$ FDocumentPage.

Gandia, J. L. (2011). Internet Disclosure by Nonprofit Organizations: empirical evidence of nongovernmental organizations for development in Spain. Nonprofit and Voluntary Sector Quarterly, vol. 40, n. 1, p. 57-78.

Gil, A. C. (1999). Métodos e técnicas de pesquisa social. 5. ed. São Paulo: Atlas.

Goulart, A. M. C. (2003). Evidenciação Contábil do Risco de Mercado por Instituições Financeiras no Brasil. São Paulo. Dissertação (Mestrado em Ciências Contábeis) - Programa de Pós-Graduação em Ciências Contábeis, Departamento de Contabilidade e Atuária, Faculdade de Economia, Administração e Contabilidade da Universidade de São Paulo.

Gandía, J. L. (2011). Internet disclosure by nonprofit organizations: Empirical evidence of nongovernmental organizations for development in Spain. Nonprofit and Voluntary Sector Quarterly, 40, n. 1, 57-78.

Gajewski, Jean-François, \& Li, L. (2015). Can Internet-based disclosure reduce information asymmetry. Advances in Internacional Accounting, vol. 31, p. 115-124.

Goulart, A. M. C., \& Carvalho, L. N. (2004). Evidenciação contábil do risco de mercado por instituições financeiras no Brasil. Revista UnB Contábil, vol. 7, n. 1, 9-32.

Hail, L. (2002). The impact of voluntary corporate disclosures on the ex-ante cost of capital for Swiss firms. European Accounting Review, vol. 11, n. 4, p. 741-773. 
Healy, P. M., \& Palepu, K. G. (2001). Information asymmetry, corporate disclosure, and the capital markets: A review of the empirical disclosure literature', Journal of Accounting and Economics, vol.31, p. 405-440.

Khan, M., Serafeim, G., \& Yoon, A. (2016). Corporate sustainability: First evidence on materiality. The Accounting Review, vol. 91, n. 6, p. 1697-1724.

Hyndman, N., \& McConville, D. (2016). Transparency in reporting on charities' efficiency: A framework for analysis. Nonprofit and Voluntary Sector Quarterly, vol. 45, n. 4, 844-865, 2016.

Ho, S. S. M., \& Wong, K. S. (2001). A study of the relationship between corporate governance structures and the extent of voluntary disclosure. Journal of International Accounting, Auditing and Taxation, vol. 10, p. 139-156.

Jensen, M. C., \& Meckling, W. H. (1976). Theory of the firm: Managerial behavior, agency cost, and ownership structure. Journal of Financial Economics, v. 3, n. 4, p. 305-360.

Kavitha, D., \& Nandogopal, R. (2011). Disclosure Studies - a commentary on the methods and measures. Indian Journal of Corporate Governance, vol. 4, n. 1, p. 29-46.

Lanzana, A. P. (2004). Relação entre disclosure e governança corporativa das empresas brasileiras. São Paulo, 2004. Dissertação (Mestrado em Administração) - Faculdade de Economia, Administração e Contabilidade, Universidade de São Paulo

Lee, R. L., \& Joseph, R. C. (2013). An examination of web disclosure and organizational transparency. Computers in Human Behavior, vol. 29, n. 6, p. 2218-2224.

Malaquias, R. F., \& Carvalho, L. F. (2008). Análise empírica da evidenciação contábil considerando a hipótese de mercados eficientes. Anais dos Seminários em Administração (Semead), São Paulo, SP, Brasil, 8.

Marston, C., \& Polei, A. (2004). Corporate reporting on the Internet by German companies. International Journal of Accounting Information Systems, vol. 5, n. 3, 285-311.

$\mathrm{Ng}$, A. C., \& Rezaee, Z. (2015). Business sustainability performance and cost of equity capital. Journal of Corporate Finance, vol. 34, p. 128-149.

O’Dwyer, B., \& Unerman, J. (2008). The paradox of greater NGO accountability: A case study of Amnesty Ireland. Accounting, Organizations and Society, vol. 33, n. 7, 801-824.

Quinteiro, L. G. L., \& Medeiros, O. R. (2005). Ambiente de evidenciação contábil e mobilidade de capitais internacionais. Anais do Congresso USP de Controladoria e Contabilidade, São Paulo, SP, Brasil, 5, outubro.

Rocha, J. (2019). Brasil já tem cerca de 400 mil Organizações Sociedade Civil. Recuperado de: https://observatorio3setor.org.br/carrossel/brasil-ja-tem-cerca-de-400-mil-organizacoesda-sociedade-civil/

Salotti, B. M., Yamanoto, M. M., \& Pimentel, R. C. (2007). Demonstração voluntária da demonstração dos fluxos de caixa e o desempenho das empresas de capital aberto no Brasil. Anais do Congresso USP de Controladoria e Contabilidade, São Paulo, SP, Brasil, 7.

Santos D. F., Costa, G. A., Correa, M. D., \& Santos, F. F. (2011). Evidenciação contábil e as práticas de governança corporativa. Anais do Congresso UFSC de Controladoria e Finanças, Florianópolis, SC, Brasil, 4, abril. 
Saxton, G., Kuo, Jenn-Shyong, \& Ho, Yi-Cheng. (2011). The Determinants of Voluntary Financial Disclosure by Nonprofit Organizations. Nonprofit and Voluntary Sector Quarterly, vol. 41, n. 6, p. 1051-1071.

Saxton, G. \& Guo, C. (2011). Accountability online: Understanding the Web-based accountability practices of nonprofit organizations. Nonprofit and Voluntary Sector Quarterly, vol. 40, p. 270-295.

Striebing, C. (2017). Professionalization and voluntary transparency practices in nonprofit organizations. Nonprofit Management \& Leadership, vol. 28, n. 1, 65-83.

Taylor, M., \& Warburton, D. (2003). Legitimacy and the role of UK third sector organizations in the policy process. Voluntas: International Journal of Voluntary and Nonprofit

Organizations, 14, n. 3, 321-338.

Tenório, F. G. (2004). Gestão de ONGs: principais funções gerenciais. 8. ed. Rio de Janeiro: Fundação Getúlio Vargas.

Tremblay-Boire, J., \& Prakash, A. (2014). Accountability.org: Online Disclosures by U.S. Nonprofits. International Journal of Voluntary and Nonprofit Organizations, vol. 26, n. 2, p. 693-719.

Verrecchia, R. E. (1983). Discretionary disclosure. Journal of Accounting and Economics, vol. 5, p. 179-194.

Verrecchia, R. E. (2001). Essays on disclosure. Journal of Accounting and Economics, vol. 32, n. 1-3, 97-180. 